International Review of Applied Engineering Research.

Volume 1, Number 1 (2011), pp. 47-59

(C) Research India Publications

https://dx.doi.org/10.37622/IRAER/1.1.2011.47-59

\title{
Experimental Investigation of Steel Fibre Reinforced Recycled Aggregate Concrete
}

\author{
Ganesh D. Awchat ${ }^{1}$, Narendra M. Kanhe ${ }^{2}$ and Shailendra S. Rathore ${ }^{3}$ \\ ${ }^{1}$ Doctoral Research Student of MIET, Salai Godhani, Hudkeshwar Road, \\ Nagpur-441204, Maharashtra, India \\ ${ }^{2}$ Professor in Civil Engineering \& Principal, \\ Guru Nanak Institute of Engineering \& Management, \\ Dahegaon, Kalmeshwar Road, Nagpur-441501, Maharashtra, India \\ ${ }^{3}$ Professor in Civil Engineering \& Principal, \\ Manoharbhai Patel Institute of Engineering \& Technology (MIET), \\ Maharashtra, India
}

\begin{abstract}
Since the era of using concrete for construction purposes, various researchers are continuously trying to improve the performance and various strengths of concrete by keeping options of economy in construction costs. One of the options is use of Steel Fibre Reinforced Recycled Aggregate Concrete (SFRRAC).SFRRAC is made by combination of Recycled Aggregate Concrete (RAC), which is obtained from wastage of materials, after building/structures demolition, natural disasters, wars etc, and the reinforcing it with steel fibers.

From the experimental investigation on RAC, it is found that strengths i.e. split tensile strength and flexural strength was increased up to $40 \%$ and $46.33 \%$ by adding steel fibers having an aspect ratio 80 with $1 \%$ volume fraction. So, an attempt is made in this work to use steel fibre having an aspect ratio 50 with minimum $30 \mathrm{~kg} / \mathrm{m}^{3}$ fibre volume fraction in RAC so as to compare various strengths with Normal Aggregate Concrete (NAC).

Present study aims at studying and comparing the performance of NAC with that of SFRRAC. For this purpose, cubes, beams and cylinders of M20 and M30 grades were casted separately for NAC \& SFRRAC.

Beams were tested under flexure, cubes for compression and stress strain behavior and cylinders for split tensile strength. From the experimental study,
\end{abstract}


it has been observed that the addition of steel fibres with fibre volume fraction $50 \mathrm{~kg} / \mathrm{m}^{3}$ in RAC, effectively increase ultimate flexural strength by $22 \%$ \& split tensile strength by $20 \%$ as compared to RAC without addition of steel fibre. Thus, SFRRAC can be preferred where the strength criteria for design \& construction are of prime importance.

Keywords: Recycled Aggregate Concrete, Steel Fibres, Steel Fibre Reinforced Recycled Aggregate Concrete.

\section{Introduction}

In today's era, it is of utmost importance that the construction processes should involve the aspects of conservation of natural resources and eco-friendliness. The problem of waste disposal especially that of demolition waste has been a major concern for planners and engineers in the developing countries. With the enormous increase in the quantity of demolition rubble, the continuing shortage of dumping sites, sharp increase in transportation and disposal cost and, above all the stringent antipollution and environmental regulations enforced in a number of countries, the demolition waste disposal problem is assuming serious and at times even alarming proportions. It is therefore no wonder that the concept of recycling the waste material and using it again in economical form has gathered momentum. The recycling of waste concrete has other benefits. One of the main environmental benefits is conservation of natural resources, especially in regions where aggregates are scare.

The option of recycling is particularly attractive in industrialized countries where waste volumes are high and resource availability is low. While the United States and Canada has lagged behind in this regard, Germany, Netherlands, Belgium and Japan have reached recycling rate up to $50 \%$. The concept of recycling demolition waste into aggregate has also provided one of the alternative materials to construction engineer who has been in search for newer material and newer technology.

There are other incentives for the consumer to use Recycled Aggregate (RA) in concrete

1. The cost of RA compares quite favorably with NA in many countries.

2. Most municipalities allow use of RA if it meets certain criteria of strength \& durability.

3. With the general need to reduce and manage waste in large proportion, the use of RA is one of the most effective ways of managing waste.

4. Lower densities of RA generally mean lower concrete densities and higher concrete yields for same volume of concrete.

The major drawback in the use of RA is their lower compressive strength, split tensile strength, flexural strength and lower modulus of elasticity. To overcome these drawbacks to some extent, it would be advisable to produce RAC with lower w/c ratio with addition of Steel Fibre (SF) in it as suggested by Dhir [1, 8], Desai [2], Shobhan [7] and Nixon [11].

Steel fibre reinforced normal aggregate concrete is finding its application to 
various fields of construction because of the improvement in strength and deformation characteristics as compared to NAC. The fibres are uniformly distributed and randomly oriented throughout volume of concrete. Thus, it is converting brittle characteristics of any concrete to ductile one as per Modera, Bairagi [5]. A significant consequence of fiber addition is therefore a substantial improvement in the resistance to the formation and growth of crack, in addition, a marginal improvement in split tensile strength \& flexural strength.

\section{Experimental Programme}

\section{Materials}

Based on physical properties of fine aggregate \& Natural Aggregate (NA), two mixes were finalized confirming to $\mathrm{M}_{30}$ \& $\mathrm{M}_{20}$ grade of NAC using Indian standard recommended method of mix design \& SP23:1982. These mixes were [1:1.72:3.22:0.47]\& [1:2.04:3.97:0.54] of $\mathrm{M}_{30} \& \mathrm{M}_{20}$ grade of $\mathrm{NC}$ respectively. Also, it was decided to use same two mixes for the preparation of RAC \& SFRRAC so as to compare the various concrete properties of NAC with it .

Ordinary Portland cement of 43 grade confirming to IS 8112 was used in all four mixes. The fine aggregate used was locally available sand of river Kanhan having specific gravity 2.71 , fineness modulus 3.28 and confirming to IS grading curve-II. Locally available parent source of crushed basalt stone aggregates of Pachgaon stone quarry near Nagpur was used in all mixes of NC confirming IS 383:1970. Recycled aggregates obtained by crushing the waste material available in concrete testing laboratory of Ready Mixed Concrete Plant of Ultra-Tech Cement Limited \& concrete testing laboratory of Geo-Tech Services at Nagpur.

Since large size particles cause concentration of stress around particles and results in the lower strength of concrete. Considering this aspect, $20 \mathrm{~mm}$ down grade size aggregate was considered suitable for medium strength concrete as per Bhantia, Chan [6]. A complete replacement of NA with RA was considered in the mixes of RAC.

Table 1: shows the physical and mechanical properties of both NA and RA.

\begin{tabular}{|l|l|l|}
\hline Tests on aggregate & $\begin{array}{l}\text { Normal(Parent) } \\
\text { aggregate (NA) }\end{array}$ & $\begin{array}{l}\text { Recycled } \\
\text { Aggregate (RA) }\end{array}$ \\
\hline Fineness Modulus & 7.49 & 5.25 \\
\hline Specific gravity & 2.983 & 2.638 \\
\hline Water absorption & $0.415 \%$ & $2.972 \%$ \\
\hline Crushing value & $13.77 \%$ & $26.18 \%$ \\
\hline Impact value & $12.63 \%$ & $27.26 \%$ \\
\hline Abrasion value & $10.66 \%$ & $29.08 \%$ \\
\hline Flakiness Index & $16.69 \%$ & $13.90 \%$ \\
\hline Elongation Index & $21.26 \%$ & $35.26 \%$ \\
\hline Soundness by $\mathrm{MgSo}_{4}$ & $0.5142 \%$ & $-0.5942 \%$ \\
\hline Soundness by $\mathrm{Na}_{2} \mathrm{So}_{4}$ & $0.4263 \%$ & $-0.4464 \%$ \\
\hline
\end{tabular}


SF required for the investigation were prepared from good quality stainless steel thin wire having a diameter of $0.60 \mathrm{~mm}$ (a) \& length of $30 \mathrm{~mm}$ (d). SF having weight density $7860 \mathrm{Kg} / \mathrm{m}^{3}$, tensile strength $1608.94 \mathrm{~N} / \mathrm{mm}^{2}$, aspect ratio 50 (a/d ratio) and satisfying other requirement was used as reinforcing material.

\section{Mix Proportion}

Since there is no standard method of designing concrete mixes incorporating RA, the method of mix design proposed by IS 10262:1982 \& SP23:1982 was first employed to design the NAC mixes and finally NA was fully replaced by RA to obtain RAC mixes as per Ravande[10]. In present experimental work, following mix proportion were taken as trial mixes confirming to $\mathrm{M}_{30} \& \mathrm{M}_{20}$ grade of concrete

Table 2: shows mix proportion \& w/c ratio for NAC \& RAC.

\begin{tabular}{|l|l|l|l|l|}
\hline $\begin{array}{l}\text { Concrete Specification } \\
\text { [grade] }\end{array}$ & Mix type & Mix proportion & $\begin{array}{l}\text { Designed w/c } \\
{[\mathrm{NAC}]}\end{array}$ & $\begin{array}{l}\text { w/c } \\
{[\mathrm{RAC}]}\end{array}$ \\
\hline $\mathrm{NA}\left[\mathrm{M}_{30}\right]$ & Mix-1 & $1: 1.72: 3.22$ & 0.47 & 0.47 \\
\hline $\mathrm{NB}\left[\mathrm{M}_{20}\right]$ & Mix-2 & $1: 2.04: 3.97$ & 0.54 & 0.54 \\
\hline
\end{tabular}

In the RAC mixes, $30 \mathrm{~kg} / \mathrm{m}^{3}, 40 \mathrm{~kg} / \mathrm{m}^{3} \& 50 \mathrm{~kg} / \mathrm{m}^{3}$ fibre volume fraction was added. The standard cubes of size $15 \mathrm{~cm} \times 15 \mathrm{~cm} \times 15 \mathrm{~cm}$ were casted for trial mixes.

Table 3: shows trial mix results of $\mathrm{M}_{30}$ and $\mathrm{M}_{20}$ for NAC \& RAC.

\begin{tabular}{|l|l|l|l|l|}
\hline $\begin{array}{l}\text { Mix } \\
\text { type }\end{array}$ & $\begin{array}{l}\text { Aggregate } \\
\text { in mix }\end{array}$ & $\begin{array}{l}7 \text { days avg. } \\
\text { compressive } \\
\text { strength }\left(\mathrm{N} / \mathrm{mm}^{2}\right)\end{array}$ & $\begin{array}{l}\text { 28 days avg. compressive } \\
\text { strength }\left(\mathrm{N} / \mathrm{mm}^{2}\right)\end{array}$ & $\begin{array}{l}\text { Cement content } \\
\left(\mathrm{Kg} / \mathrm{m}^{3}\right)\end{array}$ \\
\hline Mix-1 & NA & 28.48 & 38.21 & 379.59 \\
\hline Mix-2 & NA & 23.67 & 33.31 & 338.18 \\
\hline Mix-1 & RA & 27.36 & 34.61 & 379.59 \\
\hline Mix-2 & RA & 20.12 & 31.21 & 338.18 \\
\hline
\end{tabular}

\section{Casting and Testing Specimens}

Total 150 cubes, 90 cylinders and 90 beams of $\mathrm{M}_{30}$ and $\mathrm{M}_{20}$ grade of concrete were cast in four series. Out of which, first two series were cast for NAC and RAC using two w/c ratio $0.47 \& 0.54$ and other two series were cast by adding $S F$ with $\left(30 \mathrm{~kg} / \mathrm{m}^{3}\right.$, $40 \mathrm{~kg} / \mathrm{m}^{3} \& 50 \mathrm{~kg} / \mathrm{m}^{3}$ fibre volume fraction in RAC.

Two grades of concrete were designed in order to determine the effect on the various properties of concrete i.e. compressive strength, split tensile strength, flexural strength, stress-strain behavior in compression, pullout strength. 
First series consist of 30 cubes $(15 \times 15 \times 15 \mathrm{~cm}), 18$ cylinders $(15 \times 30 \mathrm{~cm})$ and 18 beams $(10 \times 10 \times 40 \mathrm{~cm})$ of $\mathrm{M}_{30}$ and these specimens were cast to determine compressive strength, split tensile strength and flexural strength of NAC and RAC at 7 days, 28days \& 90days. Out of total 30 cubes, 3 cubes each of NAC and RAC were tested for stress-strain behavior in compression and 3 cubes were tested to determine pullout strength of both NAC \& RAC at 28 days.

In second series, casting done in first series was repeated by $\mathrm{M}_{20}$.

Third series consist of 45 cubes, 27 cylinders and 27 beams of M30 and these specimens were cast for RAC only. The parameters varied during casting of these specimens were SF volume fraction as $30 \mathrm{~kg} / \mathrm{m}^{3}, 40 \mathrm{~kg} / \mathrm{m}^{3}$, and $50 \mathrm{~kg} / \mathrm{m}^{3}$. Out of 45 cubes, 3 cubes each of three variation of SF content were tested for stress-strain behavior in compression and 3 cubes were tested to study pull out strength at 28 days.

In fourth series, casting done in third series of $\mathrm{M}_{30}$ was repeated by $\mathrm{M}_{20}$.

Table 4: shows casting specimen details.

\begin{tabular}{|c|c|c|c|c|}
\hline \multirow{2}{*}{$\begin{array}{l}\text { Mix type } \& \\
\text { grade of } \\
\text { concrete }\end{array}$} & \multirow[t]{2}{*}{ Specification } & \multicolumn{3}{|l|}{ Specimen details } \\
\hline & & Cube specimen & $\begin{array}{l}\text { Cylinder } \\
\text { specimen }\end{array}$ & $\begin{array}{l}\text { Beam } \\
\text { specimen }\end{array}$ \\
\hline \multirow{5}{*}{$\begin{array}{l}\text { Mix-1 } \\
\& \\
M_{30}\end{array}$} & $\mathrm{NA}\left(\mathrm{NC}+0 \% \mathrm{SF}^{*}\right)$ & 15 & 9 & 9 \\
\hline & $\mathrm{RA}(\mathrm{RAC}+0 \% \mathrm{SF})$ & 15 & 9 & 9 \\
\hline & RA-1 $\left(\mathrm{RAC}+30 \mathrm{~kg} / \mathrm{m}^{3} \mathrm{SF}\right)$ & 15 & 9 & 9 \\
\hline & RA-2(RAC+ $\left.40 \mathrm{~kg} / \mathrm{m}^{3} \mathrm{SF}\right)$ & 15 & 9 & 9 \\
\hline & RA-3(RAC+ $\left.50 \mathrm{~kg} / \mathrm{m}^{3} \mathrm{SF}\right)$ & 15 & 9 & 9 \\
\hline \multirow{5}{*}{$\begin{array}{l}\text { Mix-2 } \\
\& \\
M_{20}\end{array}$} & $\mathrm{NB}(\mathrm{NC}+0 \% \mathrm{SF})$ & 15 & 9 & 9 \\
\hline & $\mathrm{RB}(\mathrm{RAC}+0 \% \mathrm{SF})$ & 15 & 9 & 9 \\
\hline & RB-1 (RAC+ $\left.30 \mathrm{~kg} / \mathrm{m}^{3} \mathrm{SF}\right)$ & 15 & 9 & 9 \\
\hline & RB-2(RAC+ $\left.40 \mathrm{~kg} / \mathrm{m}^{3} \mathrm{SF}\right)$ & 15 & 9 & 9 \\
\hline & RB-3(RAC+ $\left.50 \mathrm{~kg} / \mathrm{m}^{3} \mathrm{SF}\right)$ & 15 & 9 & 9 \\
\hline \multicolumn{2}{|c|}{ Total No. of Specimens } & 150 & 90 & 90 \\
\hline
\end{tabular}

*Steel Fibre

\section{Testing arrangement for measurement of stress-strain in compression}

Cubes were tested in Compression Testing Machine to observe the stress-strain behavior in compression. Two dial gauges were attached along the lateral direction coinciding each others and another one dial gauge was attached along applied load direction whereas the bottom of Compression Testing Machine was fixed in opposite direction to the direction of load. The load was applied at uniform rate and corresponding deformation was measured at an increment of 5 tones. During the testing of each cube, the dial gauge readings were recorded even after the failure of cube for a successive decrement of 5 tones. 


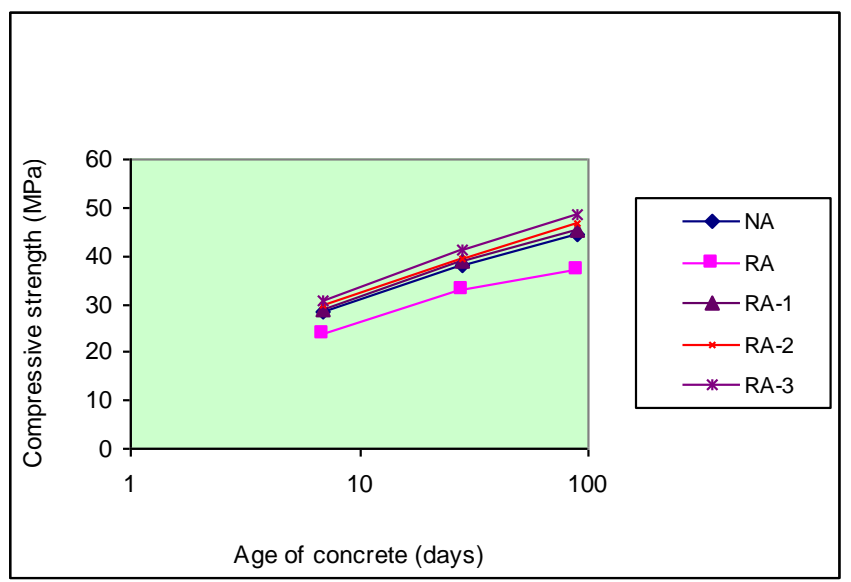

Figure 1.1: Compressive strength as a function of age.

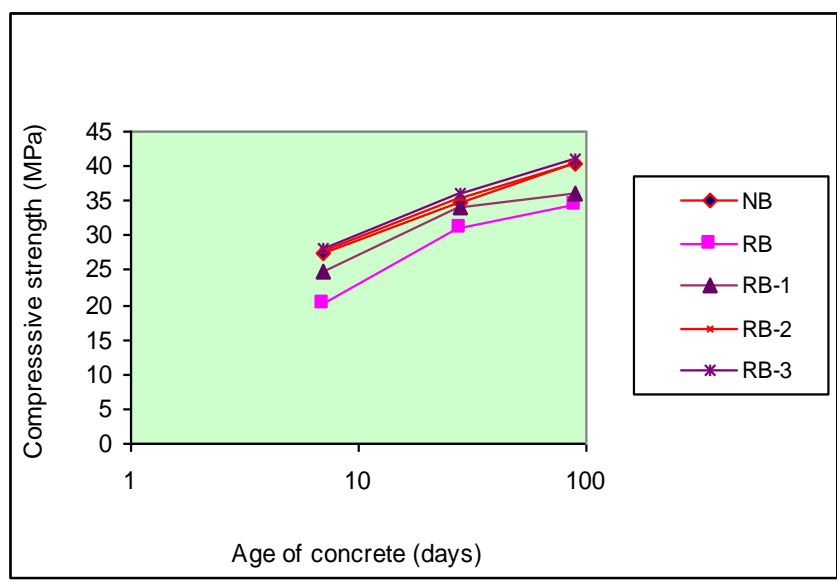

Figure 1.2: Compressive strength as a function of age.

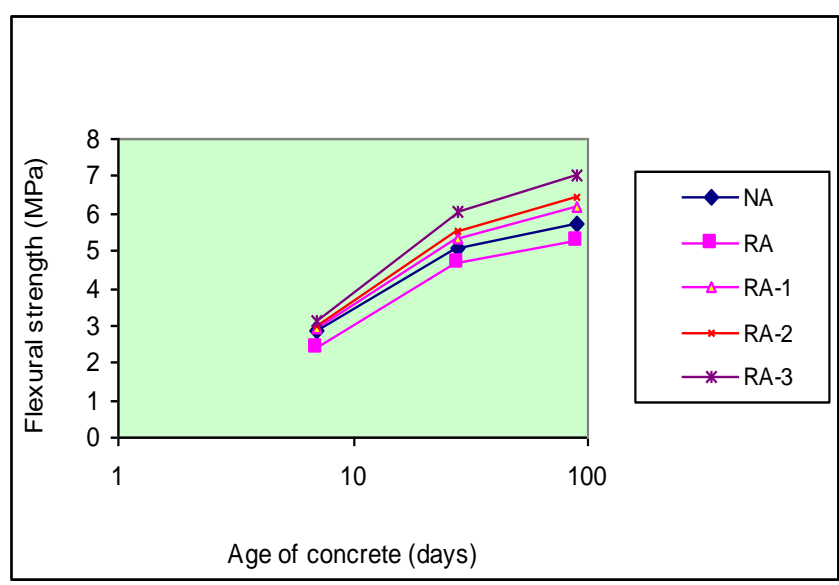

Figure 2: 1Flexural strength as a function of age. 


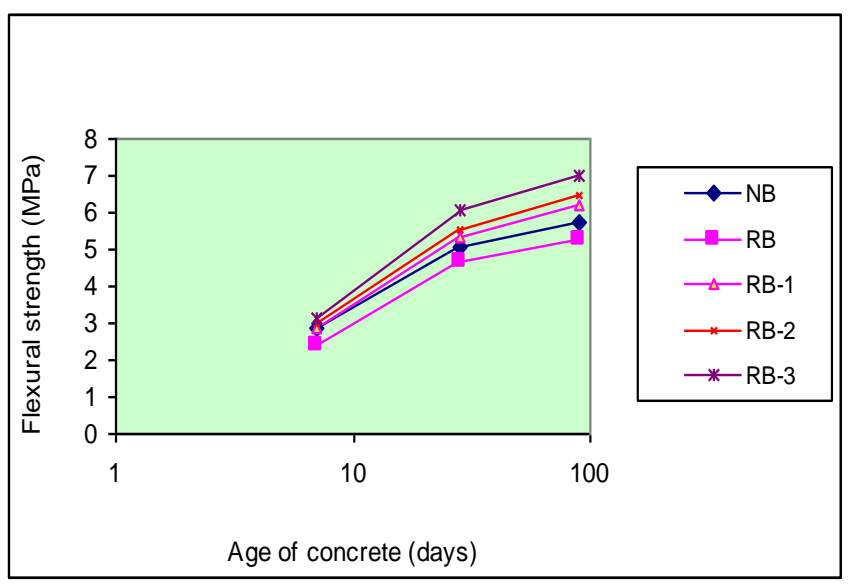

Figure 2.2: Flexural strength as a function of age.

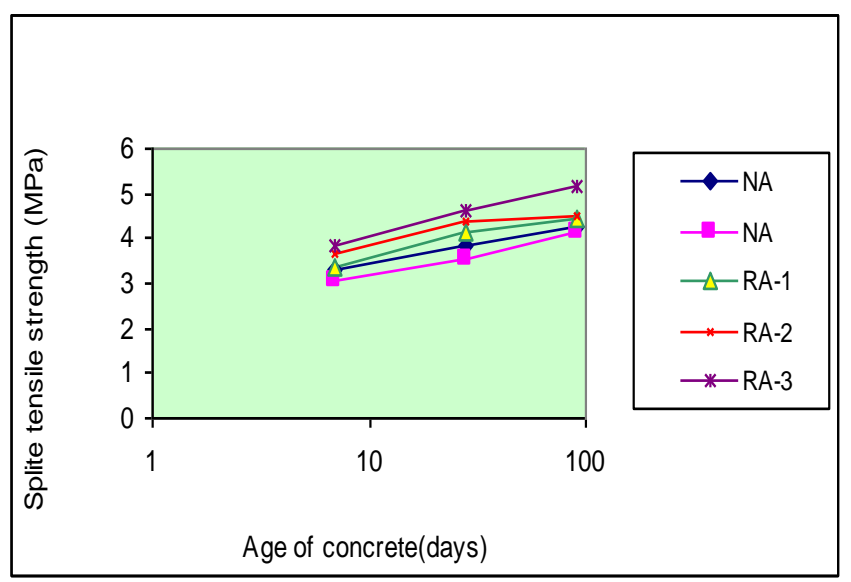

Figure 3.1: Split tensile strength as a function of age.

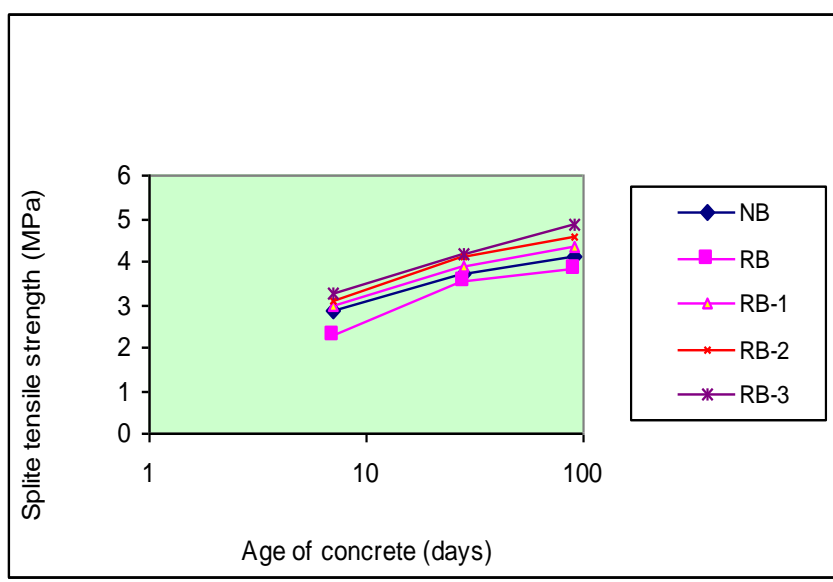

Figure 3.2: Split tensile strength as a function of age. 


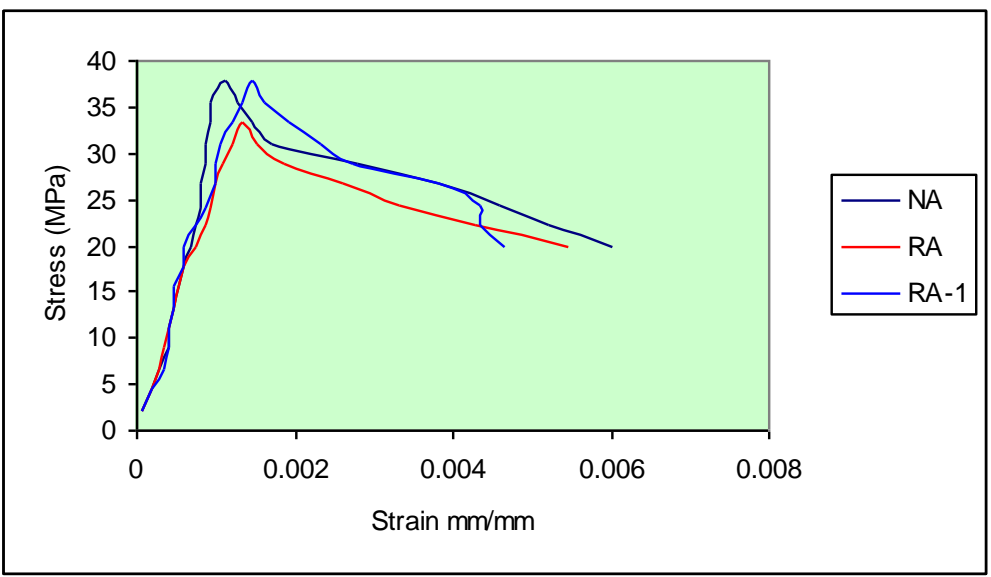

Figure 4.1: Compression stress -strain diagram for NC \& RAC, in mix-1.

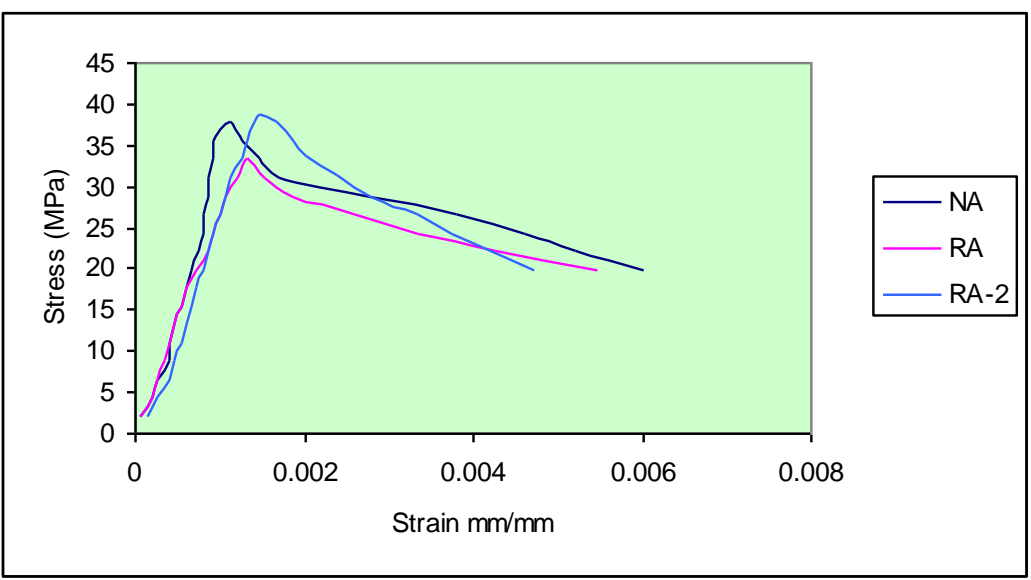

Figure 4.2: Compression stress -strain diagram for NAC \& RAC, in mix-1.

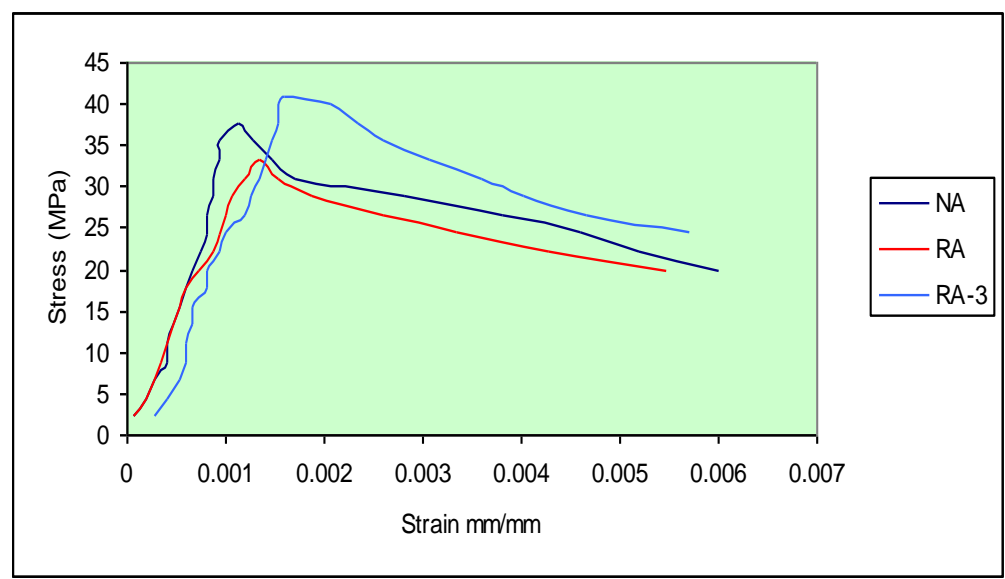

Figure 4.3: Compression stress -strain diagram for NAC \& RAC, in mix-1. 


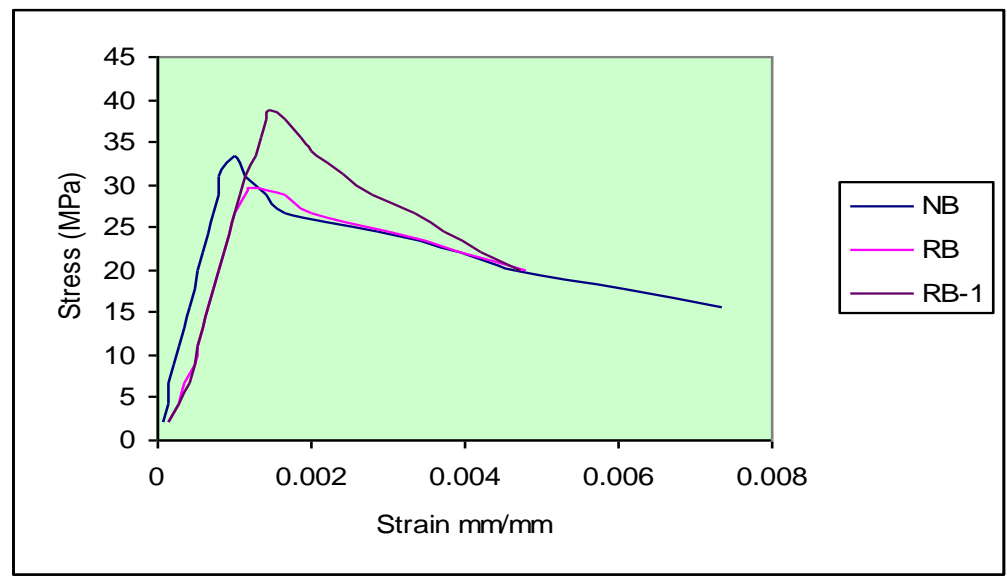

Figure 4.4: Compression stress -strain diagram for NAC \& RAC, in mix-2.

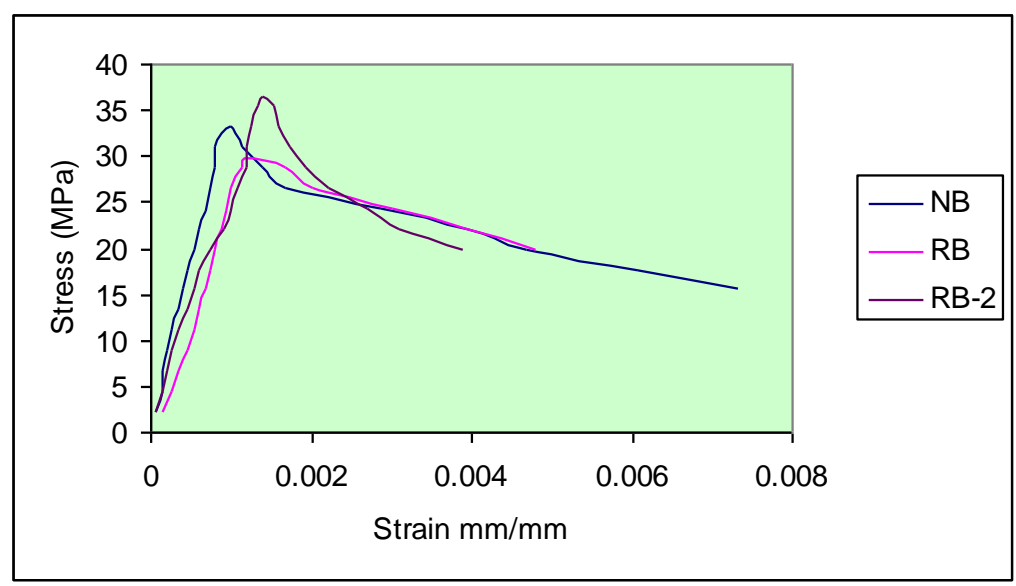

Figure 4.5: Compression stress -strain diagram for NAC \& RAC, in mix-2.

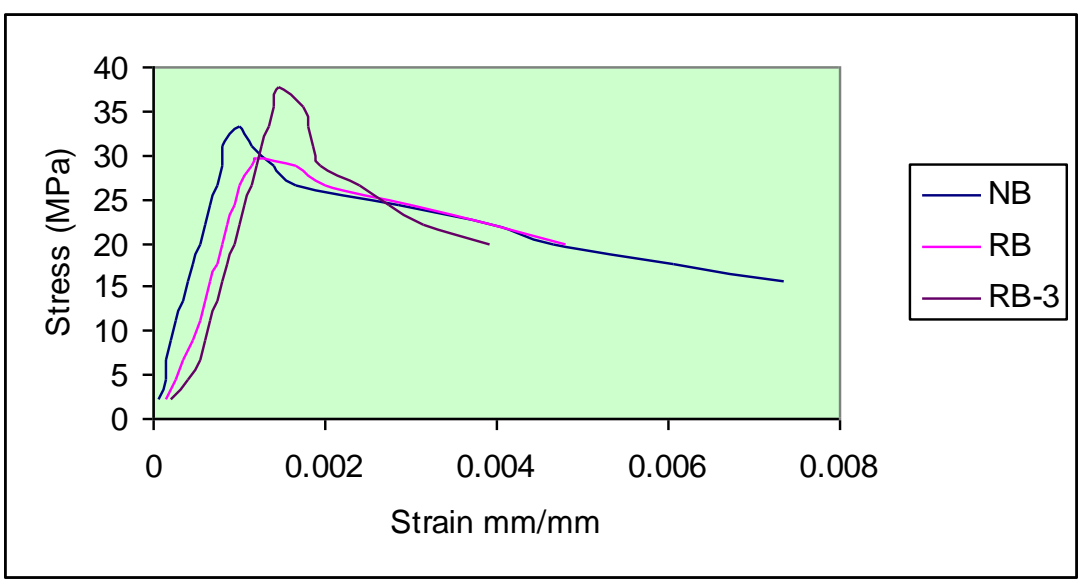

Figure 4.6: Compression stress -strain diagram for NAC \& RAC, in mix-2. 


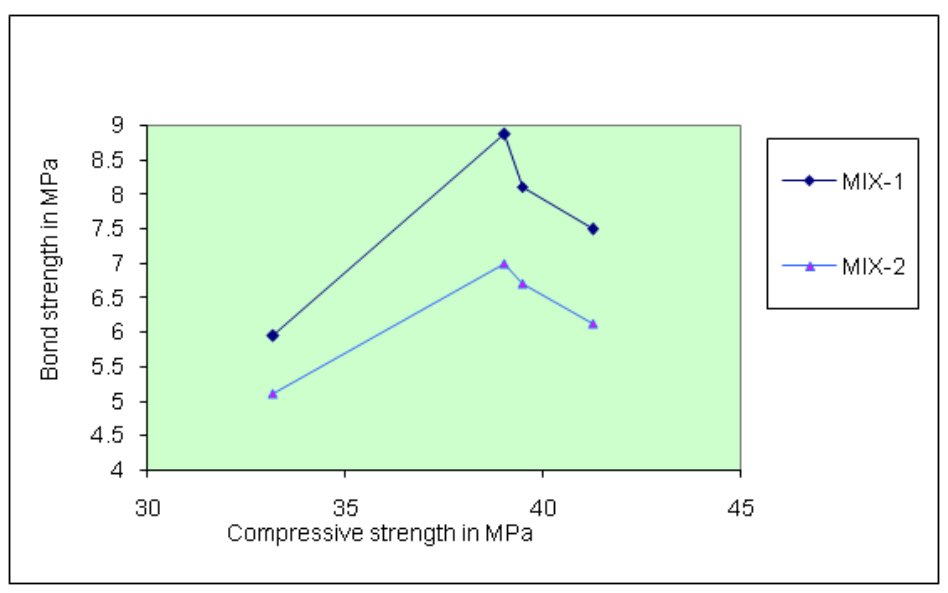

Figure 5: Comparison of compressive strength \& pullout strength, for RAC.

\section{Results and Discussion \\ Aggregate Properties \\ Specific Gravity and Water Absorption}

Tests conducted in this project work, has shown that specific gravity of RA is 2.638 , which is lower than NA i.e. 2.983. The basic reason is that RA consisting of unhydrated cement particles around the outer surface, which ultimately resulting into high porosity. RA with higher porosity resulting decrease in specific gravity. In addition to this, specific gravity of RA is within the acceptable limit as aggregate. Thus, it can be used as an aggregate for production of concrete.

From table 1, the water absorption of RA is $2.557 \%$ higher than the NA.Presoakingof aggregate is generally adopted to counterbalance the effect of water absorption. The quantity of water required for presoaking is the difference between modified w/c ratio \& designed w/c ratio Hence; it is advisable and necessary to presoak RA before using them for RAC.

\section{Crushing, Impact and Abrasion Values}

From table 1,it is seen that RA is relatively weaker than that of NA against mechanical actions. As per IS 2386 (Part-IV), the crushing and impact values should not be more than $45 \%$ for aggregate used for concrete other than wearing surfaces, and $30 \%$ for concrete used for wearing surfaces such as roads, runways and pavements. The value of crushing and impact for recycled aggregate is $26.18 \%$ and $27.26 \%$ respectively against NA is $13.77 \%$ and $12.63 \%$. The abrasion value of RA is $29.08 \%$, while for NA it is $10.66 \%$. The values of mechanical actions of RA showed that it can be used for wearing surfaces.

Soundness test on aggregate specified in IS: 2386(Part-V) is carried to decide ability of aggregate to resist excessive changes in volume as result of changes in physical conditions. As a guide, it can be taken that the average loss of weight after 10 cycles should not exceed $12 \%$ and $18 \%$ when tested with sodium sulphate and magnesium sulphate. 
RA consumes sodium sulphate and magnesium sulphate resulting into gain of weight through the pores present on outer surface whereas loss of weight is observed in NA Thus, reverse result of soundness test is observed in RA as compared to NA.

\section{Compression strength}

The variation in compressive strength of concrete as the function of age is shown in fig. Fig. $1.1 \& 1.2$ shows reduction in compressive strength of RAC as compared to NAC with same ingredient in it. When $50 \mathrm{~kg} / \mathrm{m}^{3}$ fiber was added in RAC mix-I and II, there is improvement in compressive strength by an amount $15 \%$ \& $12 \%$ respectively at 28 days. For $30 \mathrm{~kg} / \mathrm{m}^{3} \%$ \& $40 \mathrm{~kg} / \mathrm{m}^{3}$ fibre volume fraction, increase in strength is $12 \% \& 10 \%$ respectively at 28 days. Similar trend is observed at 7 days \& 90 days with different fibre volume fraction of steel fiber in it. When $30 \mathrm{~kg} / \mathrm{m}^{3}$ fiber are added in RAC, it gives slightly higher compressive strength by 5\% than the NAC.

Therefore, it is suggested that addition of $30 \mathrm{~kg} / \mathrm{m}^{3}$ fibre volume fraction in RAC will produce equal compressive strength as derived from NAC.As expected, higher w/c ratio resulted reduction in compressive strength in NAC as well as in RAC.Thus, it showed that addition of SF in RAC is not contributing for the development of additional compressive strength to significant extent.

\section{Flexural strength \& Split Tensile Strength}

From fig. $2.1 \& 2.2 \&$ fig $3.1 \& 3.2$, it shows reduction in Flexural strength \& split tensile strength of RAC as compared to NC respectively. When $50 \mathrm{~kg} / \mathrm{m}^{3}$ fiber were added, in RAC mix-I \& II, there is improvement in flexural strength \& split tensile strength by an amount $20 \%$ in both mixes \& $20 \%$ \& $15 \%$ respectively at 28 days.. For $30 \mathrm{~kg} / \mathrm{m}^{3} \& 40 \mathrm{~kg} / \mathrm{m}^{3}$ fibre volume fraction, increase in flexural strength is almost $9 \%$ in both mixes whereas increase in split tensile strength by $12 \% \& 17 \%$ respectively in mix-I \& mix- II at 28 days. Similar trend is observed at 7 days \& 90 days with different percentage of steel fiber in it. When $30 \mathrm{~kg} / \mathrm{m}^{3}$ fiber is added in RAC, it gives $22 \%$ higher flexural strength \& $20 \%$ higher split tensile strength than NC.

Thus, it is observed that higher w/c ratio resulted reduction in flexural strength \& split tensile strength in NAC as well as in RAC. Results showed that SF in RAC is useful for the development of additional strength because inferior bond in mixtures with RA \& SF allowed the material to support higher strains \& also to absorb greater post peak energies.

\section{Stress-strain behavior of concrete}

In fig 4.1 to fig 4.6, stress-strain diagrams in compression are plotted for the two mixes, comparing NAC \& RAC at an age of 28 days. The general increases in the strength (peak value of stress) due to use of NAC as compared to RAC is clear from figures. It is seen that the increase in strain at peak stress in mix-1carrying RAC.

From fig. $4.1 \& 4.4, \mathrm{RAC}$ with $30 \mathrm{~kg} / \mathrm{m}^{3}$ volume fraction of SF has increased lateral \& linear strain as compared to NAC \& RAC. Also evident is the catastrophic and sudden drop of load in the case of NAC as opposed to the slow and more stable drop of load in case of RAC with $0.4 \%$ fibre volume fraction of SF. 
In fig $4.2 \& 4.5$, it is seen that the increase in strain at peak stress in both mixes carrying RA. RAC with addition of $40 \mathrm{~kg} / \mathrm{m}^{3}$ fibre volume fraction of SF has increased value of linear strain as compared to NAC \& RAC with out addition of SF.

In fig $4.3 \& 4.6$, it is seen that the increase in strain at peak stress in both mix carrying RA. RAC with addition of $60 \mathrm{~kg} / \mathrm{m}^{3}$ fibre volume fraction of SF has increased value of linear strain as compared to NAC \&RAC with out addition of SF.

\section{Pullout Strength}

From figure 5, it is seen that the slope of the curve is proportional up to $30 \mathrm{~kg} / \mathrm{m}^{3}$ addition of steel fiber in RAC for both mixes. The pull out strength is not proportional with the increase in compressive strength. Pullout strength tends to decrease with the increase in compressive strength for both the mixes. So, it is advisable to use only $0.4 \% \mathrm{SF}$ in RAC in order to have maximum bond strength and compressive strength. The decrease in pullout strength is observed in mixes containing $40 \mathrm{~kg} / \mathrm{m}^{3} \& 50 \mathrm{~kg} / \mathrm{m}^{3}$ fibre volume fraction. It is due to presence of excessive quantity of SF leading to concretaration of fibre within volume of RAC.

\section{Conclusion}

A compression of the RA with NA showed that the former has lower specific gravity, higher water absorption capacity, low fineness modulus, lower flakiness index \& higher elongation index.. In addition, resistance to mechanical action such as impact, crushing and abrasion strength is significantly higher for RA than NA. The various strengths of RAC are comparatively lower than that of similar mix of NAC. However, with the use of SF, it may be possible to produce RAC with considerable improvement in strength. The stress-strain behavior of RAC was improved by the addition of SF compared to NAC. Improvement occurs due to presence of SF, which support higher strains and post peak energies. However, the quality of RAC is found to be improved considerable with the addition of SF.

Therefore, the results of this study provide a strong support for the feasibility of using RA instead of NA for the production of SFRRAC. However, more research studies on SFRRAC are necessary for the practical application of it.

\section{Acknowledgement}

The steel fibers required for experimental study was received from Stewols India Private Limited, Uppalwadi, Nagpur, Maharshtra, India, under their R\&D grant for doctoral research is gratefully acknowledged.

\section{References}

[1] Dhir R.., K.P., 2010, "Value Added Sustainable Use of Recycled and Secondary Aggregate in Concrete," J. ICI, pp.7-21. 
[2] Desai S.B., 2010, "Use of Industrial Byproducts and Recycled Materials in Concrete Structures -An Engineer's Perspective,"J.ICI, pp.41-48.

[3] Villagran-Zaccardi, Y.A., Zega, C.A., and Di Maio A.A., 2008, "Chloride Penetration and Bonding in Recycled Concrete,"J.ASCE, pp.449-455.

[4] Otsuki N.and etal, 2003, "Influence of Recycled Aggregate on Interfacial Transition Zone, Strength, Chloride Penetration and Carbonation of Concrete," J. ASCE, pp.443-451.

[5] Modera C.D, and Bairagi, N.K., 2001, "Shear Strength of Fiber Reinforced Concrete", J.ICI, pp. 47-52.

[6] Banthia, N., and Chan, C., 2000, "Use of Recycled Aggregate in Plain and Fiber Reinforced Shotcrete", J.CI, pp. 41-55.

[7] Shobhan, K., and Krizek. R.J., 1999, "Fatigue Behaviour of Fiber-Reinforced Recycled Aggregate Base Course,'J.Materials in Civil Engg., pp.124-130

[8] Dhir R., Henderson, N.A., and. Limachiya, M.C. 1999, "Recycled Aggregate Concrete for Sustainable Development", The Indian Concrete Journal, pp.463464.

[9] Noman, A.E., 1998, “New Fiber Technology”, J.CI, pp.57-61.

[10] Ravande, K., 1996. "Recycled Concrete- An Alternative Material of the Twenty First Century for Construction,"Int. Seminar on Civil Eng. Practices, pp.964-973.

[11] Nixon, P.J., 1977, "Recycled Concrete as an Aggregate for Concrete- a Review". J.M.C., Vol-11, No.65, pp.371-377.

[12] B.P. Hughes and N.J. Fattuthi, 1976, "The Workability of Steel Fiber Reinforced Concrete", Magazine of Concrete Research, Vol.28 (96), pp.157161.

[13] Shah, S.P., and Rangon, B.V., 1971 "Fiber Reinforced Concrete", J.ACI, pp.126-135. 